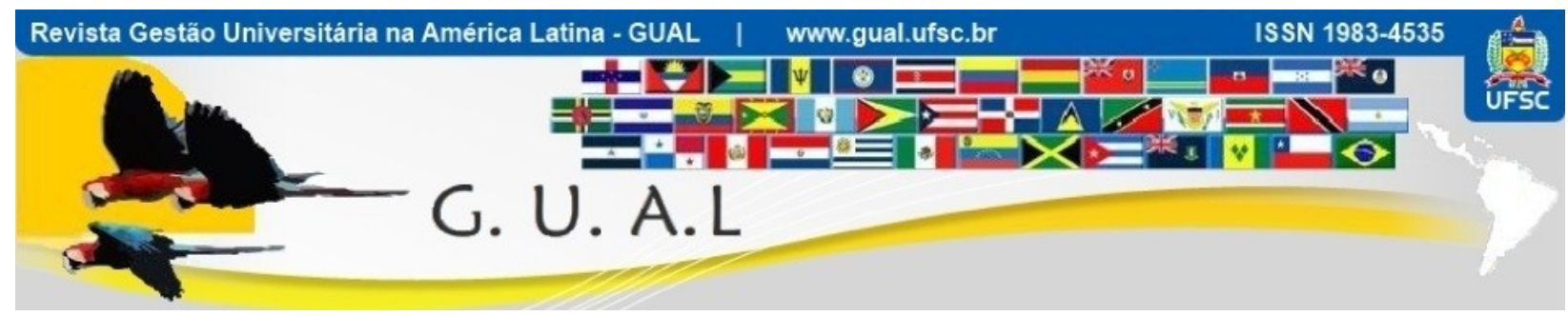

DOI: http://dx.doi.org/10.5007/1983-4535.2012v5n3p108

\title{
INSTITUCIONALIZAÇÃO DA POLÍTICA DE DESENVOLVIMENTO DE PESSOAS EM INSTITUIÇÕES FEDERAIS DE ENSINO DE MINAS GERAIS
}

\section{INSTITUTIONALIZATION OF POLICY DEVELOPMENT OF PEOPLE IN FEDERAL INSTITUTIONS TEACHING OF MINAS GERAIS}

Áurea Maria Resende de Freitas, Mestre

Universidade Federal de Viçosa - UFV aurea@ufv.br

Adriel Rodrigues de Oliveira, Doutor Universidade Federal de Viçosa - UFV arioli@ufv.br

Magnus Luiz Emmendoerfer, Doutor Universidade Federal de Viçosa - UFV magnus@ufv.br

Nina Rosa da Silveira Cunha, Doutora Universidade Federal de Viçosa - UFV ninarosa@ufv.br

Recebido em 22/setembro/2012

Aprovado em 12/outubro/2012

Sistema de Avaliação: Double Blind Review

Esta obra está sob uma Licença Creative Commons Atribuição-Uso. 


\title{
RESUMO
}

Verificar o estágio de institucionalização da política de desenvolvimento de servidores das Instituições Federais de Ensino (IFEs), na percepção de gestores de pessoas, foi o objetivo deste estudo de caso de 13 IFEs localizadas em Minas Gerais. As informações foram coletadas por meio de entrevista semiestruturada e documentos das instituições pesquisadas, tratadas por meio da análise de conteúdo. Utilizando a Teoria Institucional, tendo como contraponto as características da administração pública brasileira, possibilitou a compreensão sobre o processo de institucionalização dos cinco instrumentos gerenciais especificados na legislação de gestão de pessoas: Política Nacional de Desenvolvimento de Pessoal; Política de Desenvolvimento dos Integrantes da Carreira; Programa de Capacitação e Aperfeiçoamento; Programa de Avaliação de Desempenho; e Dimensionamento das Necessidades Institucionais. Verificou-se que tais instrumentos encontravam-se em estágios de pré e semiinstitucionalização, evidenciando que houve avanços em direção à profissionalização da força de trabalho nas IFEs. Entretanto, estas ainda carecem de ações efetivas para enfrentarem os novos temas da agenda de gestão de pessoas do setor público, ou seja, a integração da arquitetura de recursos humanos estratégicos nos processos institucionais, a vinculação da política de desenvolvimento ao planejamento institucional, a questão da democratização das relações de trabalho e a gestão por competência.

Palavras-chave: Teoria institucional. Gestão de pessoas. Desenvolvimento de pessoas. Instituição Federal de Ensino.

\begin{abstract}
Check the stage of institutionalization of development policy server of Federal Institutions Teaching (IFEs), the perception of managers of people, was the aim of this case study of 13 IFES located in Minas Gerais. Data were collected through semi-structured interviews and documents of the institutions surveyed, handled through content analysis. Using Institutional Theory, and as a counterpoint characteristics of Brazilian public administration, allowed the understanding of the process of institutionalization of the five management tools specified in legislation: the National Staff Development, Development Policy Members of Career, and Training Program improvement; program Performance Evaluation; Dimensioning and Institutional Needs. It was found that such instruments were in stages of pre-and semiinstitutionalization, showing that there is progress towards professionalisation of the workforce in the IFEs. However, they still lack effective actions to address the new issues on the agenda of people management in the public sector, the integration of the architecture of human resources in strategic institutional processes, linking development policy to institutional planning, the question democratization of labor relations and management by competence.
\end{abstract}

Keywords: Institutional theory. People management. Development of people. Federal Teaching Institution. 


\section{INTRODUÇÃO}

No setor público as mudanças no campo da gestão de pessoas acontecem de forma lenta e gradual, envolvem o rompimento de hábitos, crenças e valores radicados que configuram determinada cultura, seja ela política, organizacional ou de gestão.

Novos modelos de gestão de pessoas no serviço público são necessários para que as instituições possam atuar com êxito no ambiente social atual e implicam na necessidade de planejamento de carreiras com novas abordagens para ingresso, desenvolvimento, treinamento, avaliação de desempenho e progressão, bem como a formação de equipes de trabalho qualificadas e comprometidas com a instituição e com a sua missão.

Vincular o desenvolvimento permanente do servidor, procedimentos de gestão por competências, mensuração de desempenho e objetivos institucionais são, sem dúvida, o grande desafio intelectual e político da gestão de pessoas na administração pública, nesta incluindo as Instituições Federais de Ensino (IFEs). Além disso, o desafio da administração de IFE consiste em garantir os meios e recursos necessários para investir no desenvolvimento de seu quadro de pessoal de forma contínua, e prepará-los para atender os desafios acadêmicos e científicos.

Este artigo teve como objetivo analisar sob a ótica da Teoria Institucional e dos processos inerentes à institucionalização propostos por Tolbert e Zuckert (2010), questões relativas à legitimidade e aceitação das diretrizes instituídas e propostas pela Lei $\mathrm{n}^{\mathrm{o}}$ 11.091/2005 e pelo Decreto $\mathrm{n}^{\mathrm{o}} 5.707 / 2006$. O método utilizado foi o estudo de caso realizado, ao longo do ano de 2011, em oito universidades federais, um centro federal de educação tecnológica, três institutos federais e um campus consolidado de um dos institutos, sob a perspectiva dos gestores de pessoas das instituições estudadas.

Neste trabalho foram considerados os estágios de institucionalização propostos por Tolbert e Zucker (2010): habitualização - desenvolvimento de comportamentos padronizados para a solução de problemas; objetificação - processo de generalização do significado de uma ação socialmente compartilhada; e sedimentação - transmissão da ação e sua manutenção ao longo do tempo.

O exame do processo da gestão da política de desenvolvimento dos servidores técnico-administrativos no âmbito das IFEs torna-se essencial e justifica-se pela necessidade de sistematização de experiências que possam servir de subsídio àqueles que desejam compreender melhor o assunto. Acredita-se que o estudo das experiências recentes pode trazer 


\section{INSTITUCIONALIZAÇÃO DA POLÍTICA DE DESENVOLVIMENTO DE PESSOAS EM \\ INSTITUIÇÕES FEDERAIS DE ENSINO DE MINAS GERAIS \\ DOI: http://dx.doi.org/10.5007/1983-4535.2012v5n3p108}

contribuição significativa para que as IFEs tenham melhores condições de desenvolver seu quadro de servidores e ofereçam melhores respostas às demandas da sociedade.

Pouco da literatura tem abordagem que inclui questões relativas a estudos sobre as políticas de desenvolvimento de servidores públicos sob a ótica de sua institucionalização, então a compreensão do processo de desenvolvimento de servidores da forma abordada aqui pode ser uma aliada para o enfrentamento dos novos temas na agenda de gestão de pessoas do setor público.

Neste trabalho buscou-se responder à seguinte questão: de que forma está se dando a institucionalização das diretrizes para o desenvolvimento dos servidores técnicoadministrativos, estabelecidas por meio da Lei $n^{0} 11.091 / 2005$ e do Decreto $n^{0} 5.707 / 2006$, nas instituições federais de ensino?

Para responder esta questão buscou-se verificar o estágio de institucionalização das políticas de desenvolvimento de servidores técnico-administrativos, relativas aos aspectos estabelecidos na legislação supracitada.

Os três primeiros itens deste estudo incluem uma reflexão sobre as especificidades da área de gestão de pessoas no serviço público, o Estado brasileiro e a profissionalização dos servidores, diretrizes para o desenvolvimento do funcionalismo na administração pública e nas IFEs e os fundamentos orientadores do estudo: a teoria institucional. $\mathrm{O}$ item quatro trata dos procedimentos metodológicos, caracteriza a pesquisa, o objeto de estudo, as unidades pesquisadas, os sujeitos da pesquisa e os procedimentos da coleta de dados utilizados. O item cinco é dedicado a análise e interpretação dos dados. $\mathrm{O}$ item seis trata das considerações finais, das impressões acerca das limitações desta pesquisa e sugestões para trabalhos futuros.

\section{CONSIDERAÇÕES SOBRE A GESTÃO DE PESSOAS NO SERVIÇO PÚBLICO}

No Brasil, a longa tradição operacional da área de gestão de pessoas e o seu papel de mera operação de processos essenciais de administração de pessoas podem ser explicados pela: ausência de um movimento sindical forte e de trabalhadores mobilizados; pouca competição experimentada pelas organizações brasileiras durante o longo período em que o mercado esteve fechado ao exterior; e heterogeneidade de práticas utilizadas pelos profissionais dessa área. Um modelo estratégico de gestão de pessoas, no Brasil, é notado somente nas organizações mais estruturadas (FLEURY, 1996; DUTRA, 2002; MASCARENHAS; VASCONCELOS, 2004; LACOMBE, 2008). 


\section{INSTITUCIONALIZAÇÃO DA POLÍTICA DE DESENVOLVIMENTO DE PESSOAS EM \\ INSTITUIÇÕES FEDERAIS DE ENSINO DE MINAS GERAIS \\ DOI: http://dx.doi.org/10.5007/1983-4535.2012v5n3p108}

A adequação dos processos de gestão de pessoas no serviço público implica necessidade de planejamento de carreiras com novas abordagens para ingresso, desenvolvimento, treinamento, avaliação de desempenho e progressão (PIRES et al., 2009).

Aspectos relevantes da gestão de pessoas na administração pública são trazidos por Longo (2004), em que a gestão de pessoas não pode ser vista de forma isolada dos subsistemas de gestão das organizações; os processos de produção passam necessariamente pelas pessoas, por seu comportamento e por sua qualificação; precisa-se reduzir as restrições e especificidades do setor público como a inflexibilidades de estruturas e de processos mantidos por tradição cultural; definições de cargos pouco versáteis e pouco polivalentes; e regimes de jornada de trabalho e de organização do tempo excessivamente rígidos.

De acordo com a Organização para Cooperação e Desenvolvimento Econômico OCDE (2010) as práticas de gestão de pessoas no serviço público no Brasil têm pouco espaço para a gestão estratégica baseada em competências e desempenho, pois se concentram no controle do cumprimento das regras e normas. Avanços foram feitos pelo governo federal e isso coloca o Brasil em posição de se concentrar mais na gestão da força de trabalho de acordo com as necessidades estratégicas de governo, com atenção voltada para a eficiência.

\subsection{ESTADO BRASILEIRO E PROFISSIONALIZAÇÃO DE SERVIDORES}

No Brasil é recorrente, tanto no meio acadêmico quanto no meio político, a alegação de que são necessários o desenvolvimento e profissionalização do serviço público, para ampliar a capacidade do governo na gestão das políticas públicas e melhorar a qualidade dos serviços públicos prestados ao cidadão.

A primeira reforma administrativa da Administração Pública ocorrida na década de 1930, trazia no seu bojo que era necessária a profissionalização do setor público. Todas as reformas administrativas acontecidas, desde então, trazem a necessidade da profissionalização da administração pública. A organização de carreiras no serviço público pode, nitidamente, caracterizar como tema recorrente nas sucessivas reformas implementadas (SANTOS, 1997; LIMA JUNIOR, 1998).

A Constituição Federal (CF) de 1988, cujo foco das ações recaiu sobre o fortalecimento dos controles da administração pública, dentre outras medidas, dispôs sobre a criação do Regime Jurídico Único (RJU) para os servidores públicos. Propôs completar a reforma do serviço civil por meio da profissionalização da burocracia, com a criação da 
Escola Nacional de Administração Púbica (ENAP). Além disso, proibiu os institutos de transformação e transposição de cargos, dificultando a adoção de modelos de carreiras mais abrangentes e inteligíveis que considerem as reais necessidades institucionais, impactando nas relações de trabalho, afetando o desempenho e motivação dos servidores (ABRUCIO, 2007).

A Administração Pública Gerencial surge para contrapor a grande crise do Estado dos anos de 1980 e a globalização da economia. Esses fenômenos evidenciaram os problemas associados à adoção do modelo anterior, a Administração Pública Burocrática e impuseram a redefinição das funções do Estado e da sua burocracia (BRESSER-PEREIRA, 1997, 2004; SECCHI, 2009; CÂMARA, 2009).

No Brasil, o marco da Administração Pública Gerencial foi o Plano-Diretor da Reforma do Aparelho do Estado - PDRAE, lançado em 1995. A reforma de 1995 marcou a gestão de pessoas, no Brasil, pela adoção de mecanismos que negligenciaram a sua importância, não tendo dedicado atenção a seu indispensável ordenamento jurídico e tampouco à sua complexidade política com a adoção de uma abordagem essencialmente negativista. O foco de análise dos serviços públicos para a dimensão dos resultados econômicos primou para os ganhos financeiros decorrentes dos processos de redução do quadro de pessoal (NOGUEIRA, 2000).

O Governo Lula, iniciado em 2003, promoveu a continuidade das reformas estabelecidas no PDRAE, a exemplo de Emendas Constitucionais que alterou as regras de aposentadoria, refletiu na força de trabalho no serviço público, promovendo a sua redução. Entretanto, agregou um conjunto de ações voltadas para um Estado promotor da inclusão social e deu maior atenção aos setores da burocracia não pertencente ao núcleo estratégico, como a Educação. Ou seja, houve opção por privilegiar atividades não exclusivas e por adotar uma política oposta àquela defendida no PDRAE (NOVELLI, 2010).

Dentro da lógica do governo de continuidade, no Governo Dilma, as matérias de pessoal do serviço público, pendentes da gestão Lula, farão parte da agenda, como a regulamentação da previdência complementar e da aposentadoria especial, limitação do gasto com pessoal, avaliação e mérito e novo sistema de negociação. A tendência é de que haja um freio nas concessões de reajustes e benefícios a servidores e aposentados (QUEIROZ, 2011). 


\subsection{CONTEXTO E DIRETRIZES PARA O DESENVOLVIMENTO DOS SERVIDORES NAS IFES}

As formulações e reformulações no âmbito da educação superior e profissional trouxeram grandes transformações e mudanças nas Instituições Federais de Ensino que impactaram a área acadêmica e a área administrativa, em especial a área de gestão de pessoas.

Inseridas no cenário das mudanças da administração pública brasileira, as IFEs vêm passando, por processo de discussão, em busca de meios para atuar de maneira ainda mais alinhada com o seu papel social e institucional. Em 2003, iniciou-se o processo da Reforma da Educação Superior culminando na expansão da rede federal de ensino superior, que está entre as iniciativas de maior visibilidade do Governo Lula.

Em 2007 instituiu-se o Programa de Apoio a Planos de Reestruturação e Expansão das IFES (REUNI), por meio do Decreto $n^{\circ}$ 6.096/2007, que estabeleceu como meta para 10 anos que, a partir de 2008, que as universidades deverão dobrar o número de alunos nos cursos de graduação e permitir o ingresso de 680 mil alunos a mais nos cursos de graduação. A expansão ampliou o número de municípios atendidos pelas universidades de 114 em 2003 para 237 até o final de 2011. Foram criadas 14 novas universidades e mais de 100 novos Campi, que possibilitaram a ampliação de vagas e a criação de novos cursos de graduação. Além disso, houve a reorientação das políticas federais para a educação profissional e tecnológica. Com o advento da Lei ${ }^{0}$ 11.892/2008, criam-se os Institutos Federais (IF), que formam, hoje, a Rede Federal de Educação Profissional, Científica e Tecnológica, constituída por 38 instituições, estruturados a partir do potencial instalado nos CEFETs, escolas técnicas e agrotécnicas federais e escolas vinculadas às universidades federais (MEC, 2009).

Tendo em vista esse cenário, algumas ações importantes foram instituídas em busca de caminhos para a adequação do quadro de servidores das IFEs, a fim de atender a essa nova realidade. Destaca-se a aprovação da Lei ${ }^{\circ}$. 11.091/05 que trata da estruturação do Plano de Carreira dos Cargos Técnico-Administrativos em Educação (PCCTAE), no âmbito das Instituições Federais de Ensino vinculadas ao Ministério da Educação e o Decreto $n^{\circ}$ 5.707/2006 que estabelece a política de desenvolvimento dos servidores, que são objetos desse estudo. 


\section{FUNDAMENTOS ORIENTADORES DO NÚCLEO TEÓRICO: A ABORDAGEM INSTITUCIONAL EM EVIDÊNCIA}

Este item teve por objetivo apresentar os principais fundamentos norteadores desta pesquisa, sem a intenção de esgotar os temas, abordando aspectos da teoria institucional.

Utilizar a Teoria Institucional como norteadora desta pesquisa se justifica, pois possibilita analisar as diretrizes da política de gestão de pessoas das IFEs sob a ótica da institucionalização de seus instrumentos.

A base de análise institucional, chamada de institucionalismo de origem, principalmente sociológica, histórica e da ciência política, surge dos estudos de Merton e Selznick e é representada, sobretudo, pelas clássicas obras de Selznick (1971). O neoinstitucionalismo teve seu nascimento especialmente assinalado a partir da publicação clássica de Meyer e Rowan (1977), ganhou forças entre as décadas de 1960 e 1980 e se consolidou a partir de textos de outros renomados autores, como DiMaggio e Powell (1991), Tolbert e Zucker (2010).

Machado et al. (2005) abordaram a questão paradigmática da teoria institucional e a colocaram como teoria multiparadigmática sob uma ótica que mescla o funcionalismo com uma abordagem construtivista e interpretativista.

A institucionalização é considerada um processo ligado aos interesses que existem no ambiente organizacional com vistas à necessidade de sobrevivência, de reconhecimento e de adaptabilidade das organizações. Acontece pela repetição no uso de modos de ação em resposta às pressões internas e externas, num processo que esboça o caráter organizacional, criando a sua identidade (SELZNICK, 1966 apud CALDAS; FACHIN, 2007).

A institucionalização representa um processo condicionado pela lógica da conformidade às normas socialmente aceitas e consiste nos processos pelos quais as organizações adquirem aceitabilidade social. A conformidade se dá porque as organizações buscam legitimidade. Assim, a legitimidade torna-se imperativa para as entidades sociais (MEYER; ROWAN, 1977 apud CALDAS; FACHIN, 2007). Consiste, ainda, numa realidade socialmente construída, que é aceita como verdade e possui legitimidade (BERGER; BERGER, 2002).

O institucionalismo aponta para a necessidade de se levarem em conta as mediações entre as estruturas sociais e os comportamentos individuais. Tornou-se importante uma 
explicação tanto para ações individuais quanto organizacionais, contribuindo para as causas da institucionalização nas organizações (THÉRET, 2003).

Os ambientes institucionais exercem pressão sobre as organizações que para justificar suas atividades são motivadas a incrementar a legitimidade mediante a acomodação com as estruturas institucionais prevalecentes. As pressões das estruturas institucionais podem ser de naturezas regulativa (a legitimidade das ações dos atores está associada ao cumprimento de regras, monitoramento e punições de maneira formal que obrigam e regulam o comportamento), normativa (são prescritivas, avaliativas, incluem valores e normas que definem os significados legítimos para fins validados e revelam aspectos morais e culturais) e cognitiva (sustentam significados compartilhados entre os atores acerca das estruturas regulativas e normativas) (SCOTT, 1995).

\subsection{PROCESSOS DE INSTITUCIONALIZAÇÃO}

Neste trabalho foi utilizada a vertente sociológica da teoria institucional de Berger e Luckmann, cujos autores se preocuparam em mostrar a origem e natureza da ordem social. Argumentaram que a ordem social é baseada fundamentalmente em uma realidade socialmente compartilhada, que por sua vez é uma construção humana, criada pela interação social. Assim, a institucionalização é o processo pelo qual as ações se tornam repetidas ao longo do tempo e adquirem significados similares entre as pessoas de um grupo.

Tolbert e Zucker (2010) sugeriram, assim, um processo sequencial entre essas etapas, ou seja: a habitualização, a objetificação e a sedimentação, que possibilitam avaliar o estágio ou grau de institucionalização de determinada realidade social. Constataram que alguns padrões de comportamento social estão mais sujeitos do que outros à avaliação crítica, modificação e eliminação.

No processo de institucionalização proposto por Tolbert e Zucker (2010), a inovação é tida como elemento externo à organização e é o ponto de partida para a ocorrência da institucionalização. A inovação pode ser vista pelas perspectivas econômica, sociológica, tecnológica e organizacional, entre outras.

\subsubsection{Habitualização}

O primeiro processo é a habitualização que envolve a geração de novos arranjos estruturais e a normalização de tais arranjos. Refere-se ao desenvolvimento de 
comportamentos padronizados para a solução de problemas associados a estímulos particulares, como políticas e procedimentos. Tais processos podem ser classificados como um estágio de pré-institucionalização.

De acordo com DiMaggio e Powell (2005), nesse estágio as organizações podem adotar soluções desenvolvidas por outras, e também pode haver a imitação. Entretanto, conforme Tolbert e Zucker (2010) não há consenso a respeito da utilidade geral da inovação, e muitas podem adotar dada estrutura. Tais estruturas não serão objeto de teorização formal, e o conhecimento da estrutura será limitado, em termos de operação e de propósito.

\subsubsection{Objetificação}

O segundo processo identificado foi a objetificação, que se refere à generalização do significado de uma ação socialmente compartilhada. Envolve certo grau de consenso social entre os decisores da organização a respeito do valor da estrutura e a crescente adoção pelas organizações. A percepção dos custos e benefícios da adoção de novas estruturas pelos decisores será influenciada pela observação que estes farão do comportamento e escolhas de outras organizações (TOLBERT; ZUCKER, 2010).

Strang e Meyer (1993 apud TOLBERT; ZUCKER, 2010) defenderam que a estrutura para ser institucionalizada deve passar pelas duas tarefas da teorização: a definição de um problema organizacional genérico de insatisfação ou de fracasso organizacional que envolve a geração de reconhecimento público da existência de um padrão consistente; e a justificação de um arranjo estrutural formal particular que envolve o desenvolvimento de teorias que diagnostiquem as fontes de insatisfação ou de fracasso. A teorização atribui à estrutura legitimidade cognitiva e normativa geral. Nesse estágio, as estruturas ficaram difundidas e podem ser ditas como estando no estágio de semi-institucionalização. Tal estágio é marcado pela heterogeneidade e as estruturas têm taxa de sobrevivência mais extensa se comparadas com as que estão no processo de habitualização ou estágio pré-institucional.

No processo de objetificação, ressalta-se o papel dos atores sociais, também denominados champions, que empreendem esforços para a adoção e disseminação das práticas por meio da teorização que legitima a estrutura cognitiva e normativamente. 


\subsubsection{Sedimentação}

O terceiro processo da sedimentação refere-se à transmissão da ação e à sua manutenção ao longo do tempo. Nessa fase do processo há continuidade e perpetuação de estruturas por um período de tempo consideravelmente longo, e a estrutura sobrevive por meio de gerações de membros da organização. Nesse estágio, as estruturas ficaram sedimentadas e difundidas; fixadas, no longo prazo podem ser ditas como estando no estágio de total institucionalização.

De acordo com Zucker (1988), a total institucionalização da estrutura depende dos efeitos conjuntos da baixa resistência relativa por parte de grupos de oposição, de promoção e de apoio cultural contínuo por grupos de defensores e de correlação positiva com resultados desejados.

Segundo Berger e Luckmann (1985), é importante a compreensão do conceito de legitimação para entender a institucionalização como um processo de construção social da realidade. Para esses autores, a legitimação acontece em todos os estágios da institucionalização: “A legitimação é esse processo de explicação e justificação. A legitimação justifica a ordem institucional, dando dignidade normativa a seus imperativos práticos”(BERGER; LUCKMANN, 1985, p. 128).

No institucionalismo sobressaem as questões voltadas para o entendimento de normas e regras estatuídas institucionalmente, aspectos ambientais, grau de cooperação entre os indivíduos e as instituições, sistemas formais de organização e legitimidade institucional, bem como a capacidade das instituições em se articularem em redes.

A teoria institucional vem sendo utilizada para análise organizacional e investigação de fenômenos organizacionais, como a expansão de políticas de pessoal específicas, entre outras. Neste estudo, buscou-se entender, a partir da percepção dos gestores de pessoas nas IFEs, a adequação das diretrizes estabelecidas na legislação. Assim, essa análise à luz da teoria institucional poderá contribuir para a compreensão da institucionalização de referidas políticas no âmbito do serviço público federal.

\section{PROCEDIMENTOS METODOLÓGICOS}

$\mathrm{Na}$ consecução deste estudo foram utilizados os pressupostos próprios do paradigma interpretativo com abordagem qualitativa visando à compreensão dos agentes; no caso, os gestores da área de Gestão de Pessoas das IFEs. Buscou-se entender, por meio da perspectiva 
de cada um dos gestores, o problema proposto para análise. A perspectiva qualitativa foi escolhida por permitir revelar como a realidade foi socialmente construída e fazer vínculos com os fundamentos da teoria institucional.

A pesquisa desenvolveu-se por meio da aplicação de estudo de caso em 13 IFEs localizadas no Estado de Minas Gerais, situado na Região Sudeste do país, sendo o maior Estado em área dessa região. Apresenta diversidade regional semelhante à do próprio país.

Para a escolha dos casos, foram utilizados os seguintes critérios: Amplitude - uma vez que envolve grande parte das Instituições Federais de Ensino de Minas Gerais; Política pública - considerando que as IFEs enfrentam questões comuns inerentes ao tema desenvolvimento do quadro de servidores e a expansão e reestruturação do ensino; Relevância - a questão de pesquisa atinge diretamente os servidores do quadro e indiretamente os cidadãos que dependem das IFEs; Proximidade e facilidade de acesso à informação - as IFES estão relativamente próxima uma das outras e à facilidade de contato da autora com os gestores de pessoas.

As universidades pesquisadas possuem campi fora da sede, com exceção da UFJF e UFLA. A UFMG e a UNIFEI contam com um campus fora da sede, em que a primeira possui dois campi no município-sede e a segunda três campi no município-sede. A UFSJ dispõe de quatro campi, com atuação em oito municípios distintos. A UNIFAL, UFOP e UFV têm campi em três municípios distintos.

Também fizeram parte desta pesquisa o CEFET de Minas Gerais e o IF Minas Gerais e o seu Campus de Ouro Preto, IF do Sudeste de Minas Gerais e o IF do Sul de Minas Gerais.

Os 16 sujeitos envolvidos nesta pesquisa foram selecionados com base no critério de escolha intencional e constituem-se nos gestores responsáveis pela área de desenvolvimento de pessoas das IFEs pesquisadas. Para a seleção dos sujeitos da pesquisa, foi efetuado contato com os dirigentes de gestão de pessoas das instituições e informado sobre a pesquisa acadêmica.

Foi solicitada a indicação de profissionais que estão ou estiveram envolvidos com a política de desenvolvimento dos servidores técnico-administrativos e que tivessem condições de atender aos propósitos desta pesquisa. De posse dos nomes indicados, foi agendada a entrevista com os respectivos profissionais.

Os procedimentos utilizados para a coleta de dados foram: entrevistas semiestruturadas individuais e coletivas com gestores de pessoas; notas de campo; coleta de 


\section{INSTITUCIONALIZAÇÃO DA POLÍTICA DE DESENVOLVIMENTO DE PESSOAS EM \\ INSTITUIÇÕES FEDERAIS DE ENSINO DE MINAS GERAIS \\ DOI: http://dx.doi.org/10.5007/1983-4535.2012v5n3p108}

dados em documentos disponíveis nos sites das instituições pesquisadas. As informações constantes nos documentos das IFEs serviram para fazer a triangulação dos dados, a fim de demonstrar os fatores que determinam ou contribuem para a ocorrência do fenômeno.

As entrevistas foram realizadas pessoalmente com os gestores de pessoas das instituições, no período de agosto a novembro de 2011, tomando por base um roteiro predefinido constituído de quatro partes: caracterização da instituição, caracterização dos respondentes, questões sobre as diretrizes da Lei $n^{0} 11.091 / 2005$ e do Decreto ${ }^{0}$ 5.707/2006.

As questões foram formuladas e aprofundadas a partir da resposta do entrevistado, dando origem a questões específicas com informações pertinentes ao propósito da pesquisa. Foi valorizado o conhecimento do entrevistado que respondeu livremente às questões sem intervenção por parte do entrevistador, para não dificultar o seu raciocínio.

As entrevistas foram registradas por meio de gravação em áudio, com a permissão do entrevistado, sendo a assinatura dele recolhida em formulário próprio. Duraram de 60 a 140 minutos, totalizando mais de 17 horas de gravação que, posteriormente, foram transcritas na íntegra, buscando transpor o significado com a fidelidade da narrativa do entrevistado.

Nas pesquisas nos endereços eletrônicos das instituições, buscou-se analisar, principalmente, o Plano de Desenvolvimento Institucional, o Relatório de Gestão, o Programa de Capacitação e Aperfeiçoamento, Programa de Avaliação de Desempenho e Dimensionamento das necessidades institucionais, quando disponíveis. Algumas IFEs, quando da realização da entrevista, disponibilizaram o Programa de Capacitação e Aperfeiçoamento em documento impresso.

Para interpretação dos resultados, a análise de conteúdo foi utilizada tomando Bardin (2002) como referência principal, por permitir trabalhar com o discurso e analisar unidades além da frase, extraindo dos textos o que ele quer dizer.

Foram utilizados para a análise de conteúdo, de acordo com Bardin (2002), os pilares: pré-análise, que consistiu na descrição, preparação do material, definição dos entrevistados, transcrição das gravações, ordenação, classificação dos entrevistados; exploração e análise do material - esta etapa é fundamental, visto que as possibilidades de inferência e interpretação são dependentes dessa etapa; a inferência ou dedução; e a interpretação - momento mais fértil da análise de conteúdo, permitindo que os conteúdos recolhidos se constituam em dados ou análises reflexivas. 
Para o tratamento dos dados foi utilizada a técnica da análise temática que se baseia em operações de desmembramento do texto em unidades para descobrir os diferentes núcleos de sentido que o constituem (BARDIN, 2002). Procedeu-se à definição das unidades de registro e de contexto e à classificação e agrupamento das informações, procurando obter o sentido apontado nas respostas e nas afirmativas feitas pelo respondente para entender a sua percepção em relação ao objeto de estudo proposto.

\section{ANÁLISE E INTERPRETAÇÃO DOS DADOS}

$\mathrm{Na}$ análise dos dados a partir das questões apresentadas nas entrevistas, nos documentos das instituições, nas notas de campo e observações realizadas durante a pesquisa, foi possível identificar e caracterizar os níveis de institucionalização de cada instrumento gerencial na prática institucional.

As categorias de pesquisas relacionadas aos instrumentos gerenciais foram analisadas pelo conjunto das IFEs estudadas, considerando-se os três estágios do processo de institucionalização na perspectiva de três dimensões distintas: processo, característica dos adotantes e ímpeto para difusão. As categorias e subcategorias foram definidas pela homogeneidade, pertinência, objetividade e fidelidade, de acordo com as observações individuais e gerais obtidas do conteúdo das entrevistas e no referencial teórico, buscando estabelecer relações, verificar contradições e compreender o fenômeno.

$\mathrm{Na}$ análise de conteúdo, buscou-se, inicialmente, o material propulsor para a institucionalização do desenvolvimento dos servidores nas IFEs: a Lei ${ }^{0}$. 11.091/2005 e o Decreto $n^{0}$. 5.707/2006. As categorias iniciais foram identificadas a partir das diretrizes legais supra, relacionadas a cada um dos cinco instrumentos gerenciais especificados na legislação: Política Nacional de Desenvolvimento de Pessoal; Política de Desenvolvimento dos Integrantes da Carreira; Programa de Capacitação e Aperfeiçoamento; Programa de Avaliação de Desempenho; e Dimensionamento das Necessidades Institucionais (Quadro 1). As subcategorias foram definidas como sendo as ações necessárias à consecução dos instrumentos gerenciais estabelecidos. 


\section{INSTITUCIONALIZAÇÃO DA POLÍTICA DE DESENVOLVIMENTO DE PESSOAS EM INSTITUIÇÕES FEDERAIS DE ENSINO DE MINAS GERAIS DOI: http://dx.doi.org/10.5007/1983-4535.2012v5n3p108}

\begin{tabular}{|c|c|c|}
\hline Legislação & \begin{tabular}{c|} 
Instrumentos \\
gerenciais/ \\
Categorias
\end{tabular} & Ações previstas/Subcategorias \\
\hline \multirow{5}{*}{ 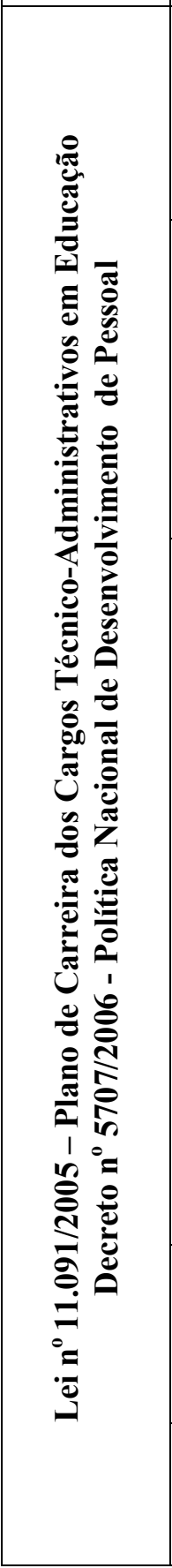 } & $\begin{array}{c}\text { A. } \\
\text { Política } \\
\text { Nacional de } \\
\text { Desenvolvimen } \\
\text { to de Pessoal }\end{array}$ & $\begin{array}{l}\text { 1. Elaborar o plano anual de capacitação da instituição, compreendendo as } \\
\text { definições dos temas e as metodologias de capacitação } \\
\text { 2. Elaborar relatório de execução do plano anual de capacitação } \\
\text { 3. Adotar o sistema de gestão por competência: Adequar as competências } \\
\text { requeridas aos objetivos das instituições; Incentivar e apoiar a capacitação } \\
\text { voltada para o desenvolvimento das competências institucionais e individuais }\end{array}$ \\
\hline & \begin{tabular}{l|} 
B. \\
Política de \\
Desenvolviment \\
$\quad$ o dos \\
Integrantes da \\
Carreira
\end{tabular} & $\begin{array}{l}\text { 1. Considerar o resultado das ações de capacitação e a mensuração do } \\
\text { desempenho do servidor complementares entre si } \\
\text { 2. Oferecer oportunidade de acesso às atividades de direção, assessoramento, } \\
\text { chefia, coordenação e assistência, respeitadas as normas específicas } \\
\text { 3. Qualidade do processo de trabalho } \\
\text { 4. Reconhecer o saber não instituído, resultante da atuação profissional } \\
\text { 5. Vincular o desenvolvimento do servidor aos objetivos institucionais } \\
\text { 6. Vincular o plano de desenvolvimento da carreira ao planejamento estratégico } \\
\text { e ao desenvolvimento organizacional da instituição }\end{array}$ \\
\hline & \begin{tabular}{c|} 
C. \\
Programa de \\
Capacitação e \\
Aperfeiçoamen \\
to
\end{tabular} & $\begin{array}{l}\text { 1. Assegurar o acesso dos servidores a eventos de capacitação interna ou } \\
\text { externamente ao seu local de trabalho } \\
\text { 2. Avaliar permanentemente os resultados das ações de capacitação } \\
\text { 3. Estimular a participação do servidor em ações de educação continuada, com a } \\
\text { oferta regular de cursos ao longo de sua vida funcional } \\
\text { 4. Garantir programas de capacitação que contemplem a formação específica e a } \\
\text { geral, nesta incluíla a educação formal } \\
\text { 5. Incentivar a inclusão das atividades de capacitação como requisito para a } \\
\text { promoção funcional e assegurar ao servidor a participação nessas atividades } \\
\text { 6. Incentivar e apoiar as iniciativas de capacitação promovidas pela própria } \\
\text { instituição, com o aproveitamento de servidores de seu próprio quadro } \\
\text { 7. Oferecer e garantir cursos introdutórios, respeitadas as normas específicas } \\
\text { aplicáveis a cada carreira ou cargo, inclusive àqueles sem vínculo efetivo com } \\
\text { a administração pública } \\
\text { 8. Priorizar, no caso de eventos externos, os cursos ofertados pelas escolas de } \\
\text { governo, favorecendo a articulação entre elas e visando à construção de } \\
\text { sistema de escolas de governo da União, a ser coordenado pela ENAP } \\
\text { 9. Promover a capacitação gerencial do servidor e sua qualificação para o } \\
\text { exercício de atividades de direção e assessoramento } \\
\text { 10. Promover ampla divulgação das oportunidades de capacitação }\end{array}$ \\
\hline & $\begin{array}{l}\text { D. } \\
\text { Programa de } \\
\text { Avaliação de } \\
\text { Desempenho }\end{array}$ & $\begin{array}{l}\text { 1. Processo pedagógico } \\
\text { 2. Vincular o desempenho do servidor às metas institucionais } \\
\text { 3. Considerar o caráter coletivo do trabalho } \\
\text { 4. Considerar o atendimento da expectativa do usuário (participação de usuários } \\
\text { na avaliação dos serviços prestados) }\end{array}$ \\
\hline & \begin{tabular}{c|} 
E. \\
$\begin{array}{c}\text { Dimensioname } \\
\text { nto das } \\
\text { Necessidades }\end{array}$ \\
\end{tabular} & $\begin{array}{l}\text { 1. Identificar força de trabalho } \\
\text { 2. Elaborar matriz de alocação de cargos } \\
\text { 3. Definir critérios de distribuição de vagas }\end{array}$ \\
\hline
\end{tabular}

Quadro 1 Instrumentos gerenciais e ações: Plano de Carreira e da Política Nacional de Desenvolvimento Fonte: Dados da pesquisa, 2011.

\subsection{ESTÁGIOS DE INSTITUCIONALIZAÇÃO DOS INSTRUMENTOS GERENCIAIS}

Foram recolhidos trechos das entrevistas com os gestores, os quais expressam significados de cada unidade de análise, buscando-se, assim, identificar o estágio de institucionalização de cada um dos instrumentos gerenciais: 


\subsubsection{Estágio de pré-institucionalização - Habitualização}

Para que a diretriz fosse classificada no estágio de pré-institucionalização, foram considerados na percepção dos gestores os principais fatores que conduzem à habitualização, especialmente em razão da orientação legal e das forças do mercado.

\subsubsection{Estágio de semi-institucionalização - Objetificação}

Para que a diretriz fosse classificada no estágio de semi-institucionalização, foram verificadas: a consolidação e difusão da diretriz por meio de consenso social entre os decisores e se houve incentivos para a adoção por meio dos Champions, representados pelos reitores e Pró-Reitores ou Diretores da área de Gestão de Pessoas. Foi observado se houve o monitoramento ou gestão para acompanhar a utilização dos instrumentos gerenciais e das ações requeridas para a sua consecução. $\mathrm{Na}$ teorização foi observada a valorização das diretrizes, dos instrumentos gerenciais e das ações pela comunidade universitária para dar conformidade aos instrumentos.

\subsubsection{Estágio de total institucionalização - Sedimentação}

Para que a diretriz fosse classificada no estágio de total institucionalização, foi observado: se houve continuidade histórica, consolidadas nas práticas de gestão e monitoramento e controle dos instrumentos gerenciais por meio de normas e sanções.

Entretanto, como as legislações que desencadearam a adoção dos instrumentos foram editadas uma em 2005 e a outra em 2006 e considerando que os ciclos de gestão das IFEs são de quatro anos, não foi possível verificar a continuidade histórica. Assim, nenhum dos instrumentos legais foi classificado no estágio de total institucionalização ou sedimentação.

Os estágios de institucionalização de cada instrumento gerencial na percepção dos gestores de pessoas das IFEs foram assim classificados:

\subsubsection{Política Nacional de Desenvolvimento de Pessoal}

Essa política prevê três importantes instrumentos gerenciais: o Plano Anual de Capacitação e o Relatório de Execução e Sistema de Gestão por Competência. Para os dois primeiros foi observado que eles estão se consolidando nas práticas de gestão de acordo com as peculiaridades de cada IFE. Esses instrumentos encontram-se no estágio de semiinstitucionalização, ou seja, no processo de objetificação. Se com o passar dos anos houver 
continuidade histórica de sua utilização por gerações de gestores, eles poderão ser sedimentados e receber a classificação de total institucionalização.

Já para o instrumento Sistema de Gestão por Competência a classificação do estágio é o de pré-institucionalização, pois a maioria das IFEs não conseguiu criar mecanismos e procedimentos internos para a sua utilização, não superou o processo de habitualização. As alegações para a não implementação desta ação são relacionadas à falta de compreensão do que se espera com o sistema e falta de conhecimento para lidar com o tema competências no serviço público, sem que haja mudança na carreira. Esse aspecto foi tratado por Pires et al. (2009), que consideraram que o emprego da abordagem das competências em instituições de governo se mostra, ainda, relativamente restrito, sobretudo em decorrência das barreiras enfrentadas pela legislação.

\subsubsection{Política de Desenvolvimento dos Integrantes da Carreira}

Esse instrumento gerencial é valorizado pelos gestores e constam nos Planos de Desenvolvimento Institucional consultados, há consenso social no que diz respeito à utilização. Algumas IFEs estão em estágio mais avançado de institucionalização, outras, buscando alternativas para a sua institucionalização. Verifica-se que a presença de fatores com a legislação, a defesa de grupo de interesse e os impactos positivos advindos de sua utilização têm impulsionado a sua legitimação.

Foram classificadas no estágio de pré-institucionalização as ações: oferecer oportunidade de acesso às atividades de direção, assessoramento, chefia, coordenação e assistência e considerar o resultado das ações de capacitação e a mensuração do desempenho do servidor complementares entre si, pois as IFEs não superaram o processo de habitualização, ou seja, a maioria não conseguiu criar mecanismos e procedimentos internos para a sua utilização de acordo com o estabelecido. A escolha para a maioria dos cargos de direção o critério é político, não é fundamentado em critérios técnicos, como formação e qualificação específicas, participação em cursos de capacitação etc.

Já para as ações como a vinculação ao planejamento estratégico e ao desenvolvimento organizacional da instituição; desenvolvimento do servidor vinculado aos objetivos institucionais; qualidade do processo de trabalho e reconhecimento do saber não instituído resultante da atuação profissional na dinâmica de ensino, de pesquisa e de extensão foi observado que, de acordo com as peculiaridades de cada IFE, elas estão se consolidando 


\section{INSTITUCIONALIZAÇÃO DA POLÍTICA DE DESENVOLVIMENTO DE PESSOAS EM \\ INSTITUIÇÕES FEDERAIS DE ENSINO DE MINAS GERAIS \\ DOI: http://dx.doi.org/10.5007/1983-4535.2012v5n3p108}

nas práticas de gestão, estão criando mecanismos de controles internos na rotina de gestão. Nesse caso, os instrumentos encontram-se no estágio de semi-institucionalização, ou seja, no processo de objetificação.

\subsubsection{Programa de Capacitação e Aperfeiçoamento}

Esse programa traz impactos positivos para as IFEs, pois há presença de defesa por grupo de interesse, por exemplo: o próprio servidor para obter a progressão por capacitação profissional necessita de certificação em programa de capacitação ou, para receber o incentivo à qualificação, precisa possuir educação formal superior à exigida para o cargo de que é titular. Dessa forma, os servidores, juntamente com os sindicatos, acabam exercendo pressão sobre a administração para propiciar o programa. Os gestores também exercem influência quando precisam de servidores capacitados para o exercício de suas atividades. Essas situações pressionam para a consecução da ação. Além disso, parece já ter sido superado praticamente em todas as IFEs a resistência das chefias para liberação dos servidores para participarem das atividades de capacitação.

Para as ações como oferecer a iniciação ao serviço público (efetivo), formação específica, geral, educação formal e gestão; estimular a participação do servidor em ações de educação continuada; assegurar o acesso dos servidores a eventos de capacitação interna ou externa; incentivar e apoiar a capacitação promovida pelas próprias instituições; incentivar a inclusão das atividades de capacitação como requisito para a promoção funcional do servidor; e promover ampla divulgação das oportunidades de capacitação foi observado que tais ações estavam se consolidando nas rotinas e práticas de gestão. Nesse caso, os instrumentos encontravam-se no estágio de semi-institucionalização, ou seja, no processo de objetificação.

Entretanto, para as ações de avaliar permanentemente os resultados das ações de capacitação com especificação do instrumento de avaliação, oferecer e garantir cursos introdutórios àqueles sem vínculo efetivo com a administração pública e priorizar os cursos ofertados pelas escolas de governo e pela Escola Nacional de Administração Pública (ENAP), constatou-se que, embora houvesse algum esforço no sentido de sua adequação, as ações ainda eram incipientes. Apenas uma instituição fazia avaliação de impacto três meses após a capacitação. Assim a classificação do estágio é o de pré-institucionalização, pois não superaram o processo de habitualização, e a maioria das IFEs não conseguiu criar mecanismos e procedimentos internos para sua utilização. 


\subsubsection{Programa de avaliação de desempenho}

$\mathrm{Na}$ análise dos dados desse instrumento gerencial, verificou-se uma diversidade de situações entre as IFEs pesquisadas. Das 13 instituições que participaram da pesquisa, somente uma não utilizava nenhum instrumento de avaliação de desempenho. Em somente uma instituição o gestor declarou que o programa, ora implantado, atendia todos os aspectos previstos na legislação. A maioria das IFEs utilizava o instrumento pró-forma, para garantir a concessão da progressão por mérito profissional aos seus servidores. Algumas IFEs estavam em processo de revisão do programa, visando à melhoria do instrumento. A maioria dos gestores declarou que os problemas na adequação do programa não se referiam ao instrumento e, sim, à cultura organizacional. Essa situação foi enfatizada por Santos e Cardoso (2001), que consideraram que até hoje a avaliação de desempenho na Administração Federal não obteve êxito nas tentativas de libertar-se da discricionariedade, da tolerância, do paternalismo, da condescendência e, mesmo, da displicência que sempre condenaram os instrumentos de avaliação dos servidores ao desuso, em pouco tempo.

Para esse instrumento a classificação é o estágio pré-institucionalização, pois a maioria das IFEs não conseguiu superar o processo de habitualização e criar mecanismos e procedimentos internos para a sua utilização. As IFEs não conseguiram êxito em estabelecer conexão entre as ações de capacitação e o desempenho do servidor, considerar na avaliação as expectativas dos usuários, utilizar o instrumento como processo pedagógico e avaliar o caráter objetivo do desempenho do servidor com as metas institucionais.

\subsubsection{Dimensionamento das Necessidades Institucionais}

Nenhuma IFE pesquisada conseguiu implementar esse instrumento e desenvolver modelo de alocação de vagas, sob várias alegações, entre elas a falta de pessoal qualifícado, poucas diretrizes da Secretaria de Recursos Humanos (SRH), ausência de modelo regulador e equipe reduzida com volume muito grande de atividades. Assim, a classificação do estágio é o de pré-institucionalização, pois as IFEs não superaram o processo de habitualização, apesar de a maioria dos gestores ter apontado esse instrumento como importante ferramenta para a alocação e distribuição eficiente do quadro de pessoal.

A análise da institucionalização dos instrumentos de gestão da política de desenvolvimento dos servidores passou pela discussão de algumas das principais ações estabelecidas na legislação e de como as IFEs conduziram os arranjos institucionais em 
função da orientação legal e das forças de mercado, com a criação de novos arranjos estruturais desencadeados a partir dessa inovação, assim como a criação de procedimentos e programas visando a utilização dos instrumentos.

Foi observado que houve crescente utilização de alguns dos instrumentos gerenciais de forma integrada nas IFEs. Observou-se, a partir das argumentações dos gestores de que as instituições adotavam determinadas estruturas e procedimentos a fim de alcançar a legitimidade transferida pelos costumes e normas aceitos coletivamente.

O consenso social sobre a importância de utilização do instrumento aumenta seu potencial de difusão nos diversos setores da instituição, assim como em outras instituições. Porém, isso acontece somente com intenso esforço de persuasão dos Champions (Reitores e Gestores de Pessoas) para a adoção de práticas alinhadas aos instrumentos gerenciais que podem levar a níveis crescentes de desempenho dos servidores e, consequentemente, da instituição.

Pode-se concluir que, na percepção dos gestores de pessoas e utilizando os critérios teóricos para caracterização dos estágios de institucionalização, existem algumas ações estabelecidas na legislação e inerentes a cada um dos instrumentos gerenciais que se encontram em fase de pré-institucionalização e outras de semi-institucionalização. Existem obstáculos para a incorporação dos instrumentos gerenciais e do conjunto de ações nos procedimentos e rotinas das IFEs.

\section{CONSIDERAÇÕES FINAIS}

A importância desta pesquisa se revela em contribuir para o avanço do conhecimento no campo de gestão de pessoas na administração pública, especificamente nas Instituições Federais de Ensino, quanto à institucionalização da política de desenvolvimento dos servidores. Contribuiu para explicar a não institucionalização de um conjunto de ações dispostas na legislação da política de desenvolvimento dos servidores.

Por ser um tema ainda foi pouco explorado no cenário nacional, esta pesquisa abre um flanco tanto na academia quanto no campo administrativo e pode servir como balizador de ações para as instituições de ensino, para o Ministério da Educação e para o Ministério do Planejamento e Orçamento.

Ficou evidenciado que houve avanços em direção à profissionalização da força de trabalho nas IFEs, com ações que tornaram possíveis a qualificação e capacitação de grande 


\section{INSTITUCIONALIZAÇ̃̃O DA POLÍTICA DE DESENVOLVIMENTO DE PESSOAS EM \\ INSTITUIÇÕES FEDERAIS DE ENSINO DE MINAS GERAIS \\ DOI: http://dx.doi.org/10.5007/1983-4535.2012v5n3p108}

parte dos servidores das instituições estudadas. Entretanto, as IFEs ainda carecem de ações efetivas para enfrentarem os novos temas da agenda de gestão de pessoas do setor público, ou seja, a integração da arquitetura de gestão estratégica de pessoas nos processos institucionais, a vinculação da política de desenvolvimento ao planejamento institucional, a questão da democratização das relações de trabalho e a gestão por competência.

Houve na maioria das universidades estudadas a elevação da área de gestão de pessoas em nível estratégico, transpondo a estrutura para o primeiro escalão da administração (transformação em Pró-Reitorias), e isso certamente trouxe consequências positivas para a área de gestão de pessoas das universidades. Embora tenha sido observado que a transformação foi mais estrutural e menos cultural, pois essa área ainda desempenha papel cartorial nas instituições e encontra dificuldades para se posicionar estrategicamente.

A gestão por competência, tema recorrente no campo administrativo, político e científico, não tem logrado êxito nas IFEs. Assim como malogrou o dimensionamento das necessidades institucionais, com proposição de modelo de alocação de vagas. Tudo leva a crer que a tentativa de transposição de instrumentos e práticas da gestão de pessoas de organizações empresariais para as organizações públicas sem os devidos ajustes e sem considerar as peculiaridades e os engessamentos constitutivos existentes na administração pública não tem obtido êxito, além de gerar problemas internos no âmbito das instituições.

A realização deste trabalho propiciou uma sensação de angústia e de descrença em relação à gestão na Administração Pública, principalmente e mais especificamente em relação à gestão de pessoas. Surgiu um conjunto maior de dúvidas e inquietações e um sentimento de que ainda está longe de se ter um serviço público baseado em princípios de justiça social.

É perturbador esse fato, mas tudo indica que as instituições de ensino no Brasil, mesmo às com ênfase em administração pública, não conseguiram gerar conhecimento para aplicação de modelos necessários a elas.

Tudo indica também que, na maioria das vezes, os dirigentes ao assumirem suas atribuições com um conjunto presumivelmente coeso de compromissos programáticos e meios para alcançá-los se perdem nas "coalizões" que os elegeram ao cargo, pois são estas que promoverão a seleção das decisões institucionais que se tornam mais políticas que racionais. Assim, as IFEs precisam cada vez mais de dirigentes capazes de liderar o processo de construção coletiva de uma visão e negociá-la não apenas no âmbito externo (Governo Federal, Ministérios, órgãos de fomento), mas também no âmbito interno, exercendo, no nível 
estratégico, a autoridade de seu cargo. Essa construção coletiva, uma vez negociada, cabe ao dirigente, como líder político, cobrar adesão à visão, mobilizando a comunidade universitária.

A pesquisa, apesar de ter envolvido 13 instituições da rede federal de ensino, consiste em um retrato aproximado de análise das políticas de desenvolvimento de servidores técnicoadministrativos no âmbito das IFEs. Representa a percepção dos gestores de pessoas, mas os outros atores (Reitores das IFEs, os servidores, a equipe de gestão de pessoas, os técnicos do Ministério do Planejamento responsáveis pela agenda de recursos humanos) também poderiam ter sido ouvidos, não fossem as limitações de tempo e recursos financeiros.

\section{REFERÊNCIAS}

ABRUCIO, Fernando Luiz. Trajetória recente da gestão pública brasileira: um balanço crítico e a renovação da agenda de reformas. Revista de Administração Pública, Rio de Janeiro, p. 67-86, 1967-2007. Edição Especial Comemorativa.

BARDIN, Laurence. Análise de conteúdo. Lisboa: Edições Setenta, 2002.

BERGER, Peter L.; LUCKMANN, Thomas. The social construction of reality. Boubleday: New York, 1967.

A construção social da realidade: tratado de sociologia do conhecimento. 7. ed. Petrópolis, RJ: Vozes, 1985.

BRESSER-PEREIRA, Luís Carlos. A reforma do estado dos anos 90: lógica e mecanismos de controle. Cadernos MARE da Reforma do Estado, v. 1, 1997.

CALDAS, Miguel P.; FACHIN, Roberto. Paradigma funcionalista: desenvolvimento de teorias e institucionalismo nos anos 1980 e 1990. In: CALDAS, Miguel P.; BERTERO, Carlos Omar. Teoria das organizações. São Paulo: Atlas, 2007.

CÂMARA, Leonor Moreira. O cargo público de livre provimento na organização da administração pública. Revista de Administração Pública, Rio de Janeiro, v. 43, n. 3, p. 635-59, maio/jun. 2009.

DELLAGNELO, Eloise Helena Livramento; SILVA, Rosimeri Carvalho. Análise de conteúdo e sua aplicação em pesquisa na administração. In: VIEIRA, Marcelo Milano Falcão;

ZOUAIN, Deborah Moraes (Org.). Pesquisa qualitativa em administração: teoria e prática. Rio de Janeiro, RJ: Editora FGV, 2005. p. 97-118

DIMAGGIO, Paul J.; POWELL, Walter W. The new institutionalism in organizationalanalysis. London: Sage, 1991. 
. A gaiola de ferro revisitada: isomorfismo institucional e racionalidade coletiva nos campos organizacionais. Revista de Administração de Empresa, Rio de Janeiro, v. 45, n. 2, p. 74-89, 2005.

DUARTE, Jorge; BARROS, Antonio (Org.). Métodos e técnicas de pesquisa em comunicação. São Paulo: Atlas, 2009. 380 p.

DUTRA, Joel Souza. Gestão de pessoas: modelo, processos, tendências e perspectivas. São Paulo: Atlas, 2002.

FACHIN, Roberto C.; MENDONÇA, J.; RICARDO, C. de. Selznick: uma visão da vida e da obra do precursor da perspectiva institucional na teoria organizacional. In: VIEIRA, Marcelo M. F.; CARVALHO, Cristina A. (Org.). Organizações, instituições e poder no Brasil. Rio de Janeiro, RJ: FGV, 2003.

FLEURY, Maria Tereza Leme; FISCHER, Rosa M. Cultura e poder nas organizações. São Paulo: Editora Atlas, 1996.

LACOMBE, Francisco. Recursos humanos: princípios e tendências. São Paulo, SP: Saraiva, 2008.

LIMA JUNIOR, Olavo Brasil de. As reformas administrativas no Brasil: modelos, sucessos e fracassos. Revista do Serviço Público, Brasília, v. 2, n. 2, p. 5-31, abr./jun. 1998.

LONGO, Francisco. Mérito y flexibilidad: lagestión de las personas em las organizaciones del sector público. Paidós Ibérica: Barcelona, 2004.

MACHADO DA SILVA, Clovis L.; FONSECA, Valéria Silva da; CRUBELLATE, João Marcelo. Estrutura, agência e interpretação: elementos para uma abordagem recursiva do processo de institucionalização. Revista de Administração Contemporânea, v. 9, Artigos da BAR, p. 9-39, 2005. Edição especial.

; GONÇALVES, Sandro A. Nota técnica: a teoria institucional. In: CLEGG, Stewart R.; HARDY, Cynthia; NORD, Walter R.; CALDAS, Miguel; FACHIN, Roberto; FISCHER, Tânia (Org. bras.). Handbook de estudos organizacionais: modelos de análises e novas questões em estudos organizacionais. $5^{\mathrm{a}}$ reimpressão. São Paulo, SP: Atlas, 2010. p. 218-225.

MASCARENHAS, André Ofenhejm; VASCONCELOS, Flavio Carvalho. Tecnologia na gestão de pessoas - Estratégias de autoatendimento para o novo RH. São Paulo, SP: Editora Thomson Learning, 2004.

MEYER, John W.; ROWAN, Brian. Institutionalized organizations: formal structures as myth and ceremony. The American Journal of Sociology, v. 83, n. 2, p. 340- 63, 1977.

NOGUEIRA, Roberto Passos; SANTANA, José Paranaguá de. Gestão de recursos humanos e reformas do setor público: tendências e pressupostos de uma nova abordagem. In: Workshop on Global Health Workforce Strategy, França, 2000. 
NOVELLI, José Marcos Nayme. A questão da continuidade da política macroeconômica entre os governos Cardoso e Lula (1995-2006). Revista de Sociologia e Política, 2010.

PIRES, Alexandre Calil... [et al.]. Gestão por competências em organizações de governo. Brasília, DF: ENAP, 2009. 100 p.

QUEIROZ, Antônio Augusto de. Perfil, propostas e perspectivas do Governo Dilma. Brasília, DF: DIAP, 2011. 120 p.

SANTOS, Luiz Alberto dos. Reforma administrativa no contexto da democracia: a PEC $\mathrm{n}^{\circ}$. 173/95, suas implicações e adequação ao Estado brasileiro. Brasília, DF: Diap e ArkoAdvice Editorial, 1997. 296 p.

; CARDOSO Regina Luna dos Santos. Avaliação de desempenho da ação governamental no Brasil: problemas e perspectivas. In: Concurso de Ensayos del Clad "Control y Evaluación del Desempeño Gubernamental", 15, 2001, Caracas. Resumens... Caracas, Primer Premio.

SCOTT, William Richard. Institutions and organizations. London: Sage Publications, 1995. SECCHI, Leonardo. Modelos organizacionais e reformas da administração pública. Revista de Administração Pública, Rio de Janeiro, v. 43, n. 2, p. 347-69, mar./abr. 2009.

THÉRET, Bruno. As instituições entre as estruturas e as ações. Lua Nova, n. 58, p. 225-254, 2003.

TOLBERT, Pamela S.; ZUCKER, Lynne. Institutional sources of change in the formal structure of organizations: the diffusion of civil service reform, 1880-1935. Administrative Science Quarterly, v. 28, n. 1, p. 22-39, 1983.

; ZUCKER Lynne G. A institucionalização da teoria institucional. In: CLEGG, Stewart R.; HARDY, Cynthia; NORD, Walter R. (Org.). CALDAS, Miguel; FACHIN, Roberto; FISCHER, Tânia (Org. bras.). Handbook de estudos organizacionais: modelos de análises e novas questões em estudos organizacionais. $5^{\text {a }}$ reimpressão. São Paulo: Atlas, 2010. p. 194-217. 